\title{
Methodologies for Sustainable Energy Action Plan design and monitoring applied to the Municipality of Avezzano, Abruzzo Region, Italy
}

\author{
Andrea Cinocca $^{1 *}$, Luca Di Paolo ${ }^{1}$, Simona Abbate ${ }^{1}$, Roberto Cipollone ${ }^{1}$. \\ ${ }^{1}$ University of L'Aquila, Department of Industrial and Information Engineering and Economics, Via G. Gronchi 18, \\ L’Aquila, 67100, Italy
}

\begin{abstract}
The increasing attention and sensitivity to issues related to Global Warming and Climate Change are strengthening the actions and policies related to Sustainable Development trying to give to this concept a clearer engineering dimension. Not only policymakers are involved in this aim and experts of interdisciplinary aspects but also the irreplaceable involvement of citizens which with their behavior can make the difference and get much closer to the seventeen goals of the sustainable development by 2030. In this framework, the Territorial Energetic and Environmental Planning provides operational solidity to the concept of Sustainable Development, giving more responsibility to local administrations (as it is due according to subsidiarity), with the Central Government that guarantees the respect of the principles of Subsidiarity and Glocalization. Province of L'Aquila (in the Abruzzo Region, Italy) has been a leading player of this program and, in 2012, has realized the ambitious goal of having favored a Covenant, joining all the 108 Municipalities of the Province. Department of Industrial and Information Engineering and Economics (DIIIE) of the University of L'Aquila designed the Sustainable Energy Action Plants (SEAP) and the monitoring phase of all the Municipalities through a scientific methodology which matched the goal of SEAPs with the dimension of the Municipality. In order to go deep into SEAP's analysis, in this paper Authors describes the second uploading and necessary steps: a quantitative analysis of the Baseline Emission Inventory, the quantification of the SEAPs planning actions and the definition of the Monitoring Emission Inventory. This second step was done for the Municipality of Avezzano, one of the main Municipality of the L'Aquila Province, and gave the quantitative dimension of the $\mathrm{CO}_{2}$ emissions referred to the year 2017, compared with 2005 baseline emissions. The reduction commitments to be reached in 2020 defines the present distance to the target.

Keywords: Sustainable Energy Action Plan; SEAP; Energy Planning; Covent of Mayors.
\end{abstract}

\section{Introduction}

The mitigation of Climate Change related to Global Warming (GW) is the most important challenge to be taken up considering that it represents an emergency whose solution can no longer be delayed. European Union (EU) is facing the GW concern with a stronger force than any other Countries, firmly following the concept of "glocalization" from a political point of view. This challenge justifies the implementation of shared programs with common rules in order to guide our Society towards a Sustainable Development (SD), matching the three areas referred to environmental, economic and social dimensions. The European 2030 Agenda, [1], identified seventeen goals (Sustainable Development Goals, SDGs) for SD and this starts to give practical consistency to the concept of "Sustainability" which risked to be confined inside an intellectual domain, even though interesting. Goals n. 7 (Affordable and Clean Energy), n. 11 (Sustainable Cities and Communities), n. 13 (Climate Action) are directly close to the energy production and collective use of it and focused directly to goal n. 13 referred to Climate Change defense. EU just issued, in 2008, the "20-20-20 Climate-Energy Package", [2], active from 2009 until 2020 and aims to achieve the goals of: a) $20 \%$ reduction in energy consumption compared to Business as Usual (BaU) 2020 projection; b) increase up to $20 \%$ in the use of renewable sources in energy consumption in 2020 ; c) $20 \%$ reduction in $\mathrm{CO}_{2}$ emissions in 2020 compared to the 2005 value. These courageous positions were assumed by many other Countries or larger

* Corresponding author: andrea.cinocca@univaq.it 
geographical contexts and today these quantitative goals are more or less of universally recognized as targets. These principles and objectives have been adopted by the Municipalities (the lowest political responsible environment), thanks to the "Covenant of Mayors" program (CoM). The Covenant invites Municipalities who signed it all over the World to link together in order to share different experiences and possibilities to reduce Greenhouse gases (GHG) emissions. In this program, Public Administrations (PAs) are invited to adopt a Sustainable Energy Action Plan (SEAP) in order to produce a diagnosis of the energy consumption and to put in evidence the role for energy saving and the use of renewable sources to achieve the $\mathrm{CO}_{2}$ reduction target, at least, 20\% by 2020,[3]. SEAPs are voluntary operational tools conceived by the EU for the implementation of 2020 and 2030 European commitments for Municipalities. SEAPs invite production of energy and its consumption in different final uses to be seen inside an integrated approach in which awareness directly expressed by final users is a key point and the overall environmental interactions primarily with the atmosphere is focused to the emissions of GHG. Indeed, the Municipalities have a crucial role considering that urban areas worldwide are responsible for almost $80 \%$ of total GHG, [4]. All the studies carried out have produces a method for the SEAP compilation, analysis and monitoring. Every phase has: steps, tools and subjects involved, [5], [6], [7]. Some differences in the analysis approach depend on the size of the city, [8], [9], some depend on the contextual factors as the level of political will, administrative routines, individual choices or other factors, [10]. Every model was based on the data collection process for the BEIs and MEIs, but it's important to involve the stakeholders and the citizens. In some report a "participatory system mapping", [11], was made, in which the relation between people, economy, society, energy and GHG emissions were recorded. Through a broad involvement, the social, economic and environmental interactions could be measured and processed to obtain some future scenarios. So, the analysis and monitoring of the energy use, energy optimization and the GHG emissions are significant elements but without the study of the interactions among all dimensions of the sustainability it would be impossible to set energy targets and really achieve the objectives. The "action plans" express a city's vision to become energy independent and resilient, [9], and focused to reduce the GHG emissions. In 2015 a new Covenant of Mayors for Climate and Energy was made, in which the purpose to create synergy in terms of methods and actions to limit $\mathrm{CO}_{2}$ emissions were officially stated with a tool called "SECAPs - Sustainable Energy and Climate Action Plans". However, the preparation of the SEAP is only the first step for a correct planning and energy management of the territory which, in reality, is continuously evolving. In fact, during a SEAP's implementation the activity requires a detailed and ceaseless monitoring of the actions carried out by the Administrations: it is mandatory (and advisable too) that, every two years and with different degree of detail, the Plan must be revised, the distance to the target reevaluated and, eventually, stronger actions and a deeper involvement favored. This should happen till to the reaching of the first target time fixed at 2020. One important aspect is that Municipalities are quite different in terms of size, population, climate conditions, consumptions and also that they are differently economically oriented: this means that Municipalities could display quite different resources to the SEAP implementation and monitoring. Small villages don't have the same possibilities and expertise of medium and large Cities; therefore, the availability of tools and procedures easily implementable is of particular interest. A common indispensable feature is that the authorities' decision must be based on a bottom-up approach, based on city's needs, [9].

The paper deals about the methodology used to design the SEAP of the City of Avezzano, a Municipality of about 42,000 inhabitants whose economy is mainly based on the agroindustrial economy of the Fucino's Plateau. Handicraft and tourism represent a secondary but still important part of the economy as well as services related to the light duty industrial disctricts that are nearby. The size of the city has been chosen considering that it has the most frequent dimension of population in Italy. So, a Municipality which deserves attention concerning the SEAP derivation supported by a well organized procedure being not so small to accept a SEAP methodology simplified and done using country-independent data as it happens for smaller cities. The study presents the Baseline Emission Inventory (BEI), its $\mathrm{CO}_{2}$ dimension, the distance to the target with respect to the european commitments by 2020 . The elaboration of the MEI has been also presented offering a procedure to refine and reorient every two years the set of actions to fulfill the european goal by 2030 .

\section{Covenant of Mayors in the Province of L'Aquila}

The Covenant of Mayors is the World's largest political engagement for local climate and energy actions. It was launched in 2008 in Europe with the ambition to gather local governments voluntarily committed to achieving and exceeding the EU climate and energy targets brings together thousands of local governments following a "bottomup" approach. Actually, the Covenant initiative had the adhesion of about 10,000 signatories in 60 countries for 320 million inhabitants. Italy have the primacy for adhesion with 4,730 signatories and about over 50 million inhabitants 
involved, [12]. In 2012, the 305 Municipalities of Abruzzo Region (Italy) joined the CoM aimed to reach the EU voluntary target of reducing local $\mathrm{CO}_{2}$ emissions of about $20 \%$ by 2020 . In particular, the Province of L'Aquila (one of the four provinces in the Abruzzo Region), Territorial Coordinator of the local CoM, [13], had the adhesion of all its 108 Municipalities with the commitment to draft specific SEAPs, [14]. Economic funds have been allocated, coming from the "POR FESR 2007-2013, Axis II-Energy" program, assigned for the preparation of the municipal SEAPs and for the implementation of demonstrative efficiency measures in energy saving and distributed generation from renewable energy production, [15]. In fact, the regional program allowed to sustain from a financial point of view the realization of demonstrative $\mathrm{CO}_{2}$ saving actions for the Public Administration, conditioning the submission through an incentive mechanism to support the Covenant. The program funded these actions with contributions from $50,000 €$ to $400,000 €$, according to the number of inhabitants of each Municipality, for a global fund of 6.5 million $€$ for 6 specific actions: energy saving improving transmittance in transparent and opaque surfaces for public buildings (thermal insulation), energy efficiency effect on the public street lighting using LED light, energy efficiency improving on thermal plants in existing public buildings and replacement of old fossil-fueled heating plants by biomass heating plants, renewable distributed energy generation using photovoltaic plants and combined actions, among the previous ones.

The Department of Industrial and Information Engineering and Economics of the University of L'Aquila (DIIIE), through a scientific cooperation appointed by the Province of L'Aquila, developed a technical role in the project which consisted in the implementation of a methodological approach for the SEAPs drafting: in particular, the drafting of the BEI, the energy quantification of the actions financed by the CoM (and of the relative emissions for each action), the proposal of specific actions for each municipality in order to achieve the objective defined through a set of actions that could also guarantee an economic intervention, the availability to monitor the different phases till the 2020 target. SEAPs require the implementation of a specific methodology that includes energy territorial planning, political consultation, territorial customization and remote management of the "My Covenant" portal. SEAP document should not be interpreted as a rigid and binding instrument, but rather as a flexible tool, open to changes: any variations must be reported in order to update the pre-fixed goals of the plan and to redefine the actions to reach the objectives. Table 1 describes a SEAP process.

Table 1. Sustainable Energy Action Plan phases.

\begin{tabular}{|c|c|c|c|}
\hline Phase & Activity & Phase & Activity \\
\hline $\begin{array}{c}\text { Activation } \\
\text { [A] }\end{array}$ & $\begin{array}{l}\text { Commitment and Covenant signature; Adaptation of } \\
\text { the Municipality structures; Support to stakeholders. }\end{array}$ & $\begin{array}{l}\text { Implementation } \\
{[C]}\end{array}$ & Implementation of the planned actions. \\
\hline $\begin{array}{l}\text { Planning } \\
{[\text { [B] }}\end{array}$ & $\begin{array}{l}\text { Evaluation of the current situation; Definition of } \\
\text { long-term vision; Plan drafting and approval. }\end{array}$ & $\begin{array}{l}\text { Monitoring } \\
\text { [D] }\end{array}$ & $\begin{array}{l}\text { SEAP Monitoring; Sending the } \\
\text { Monitoring report; SEAP review. }\end{array}$ \\
\hline
\end{tabular}

The main objective is to apply the cyclical process (from A to D) implementing the actions to contain GHG emissions in order to achieve the predefined objective and bringing not only environmental but also social and economic development, in compliance with the principles of the "20-20-20 Climate-Energy Package". SEAPs focus its interventions within the competence of the local authority, both on the public and private sectors, in order to transmits to the citizens a conscious spirit about global environmental problems to live their daily lives in a more sustainable way, persuaded by good energy practices. Direct public engagement was considered a good practice in local climate mitigation action by small and medium-size cities, [16].

In the face of this commitment (SEAP implementation and monitoring phase management), in the followings the Authors present the methodological approach developed with the intention of providing operational guidelines for generalizing the drafting of a SEAP.

\section{SEAP methodologies and BEI drafting}

The SEAP is a document that reveals how the CoM signatories intend to pursue the goal of reducing $\mathrm{CO} 2$ emissions, pre-set for 2020, associated to energy consumptions for a specific base year (2005). The BEI collects data that represent the reference situations for the interventions. In order to achieve greenhouse emissions' aim set by the European Union by 2020, a campaign of monitoring actions is required, in order to verifies and validates the energy and environmental planning tools. Moreover, a quantitative monitoring carried out with the Monitoring Emission Inventory (MEI) is provided. The monitoring is essential to the concrete realization of interventions and to evaluation the SEAP, [17]. BEIs and MEIs present the same structure and establish the amount of equivalent $\mathrm{CO}_{2}$ emitted by the 
energy flows in the geographical area of the Municipalities, broken down by sector and by energy vector and sources. Their implementation provided an in-depth study of the energy flows for all the Municipalities of the Province.

For the data processing, various methodologies have been developed following the approach suggested by the European Commission guidelines referring the BEI items in the transport, residential and tertiary sector, [18]. Industrial sectors, as indicated also by the EC, were not considered because not directly influenced or guided by Municipalities. In the following sections, some guidelines developed for generalizing the drafting of a SEAP are presented.

\subsection{Methodological approach and energy flows modeling}

In this paragraph a detailed review of models used to calculate every electrical and heating energy flow in the municipal territory, expressed in MWh, is presented.

Transport sector (private and commercial): The transport sector has two contributions, private and commercial: for both of them the contribution of road transport is the only one considered, [19], [20]. The exclusion of highway sections from energy balance is justified considering they are not directly dependent from Municipalities. For private transport, only gasoline, diesel and LPG cars are considered, as the contribution of other motor vehicles and other power sources is not significant. The energy flows in the municipality territory are obtained starting from the regional fuel sales data (lgasoline, $l_{\text {diesel }}, l_{\text {LPG }}$ ), and the regional fuel vehicular distribution [21]: their ratio establishes three fuels regional sales for each vehicle, that are multiplied by vehicles' number in the Municipality (estimated by considering a linear correlation with inhabitants' number). The result (eq. 1) represents the consumed fuel (1), for the three considered energy vectors, for private transports in the Municipal territory.

$$
\begin{gathered}
l_{i, \text { munic }}=\frac{l_{i}}{\text { vehicles }_{i}} \cdot \text { vehic }_{i, \text { munic }} \\
l_{\text {diesel }}=\text { n.truck } \cdot \frac{\mathrm{km}}{\mathrm{km} / \mathrm{l}} \\
M W h_{\text {heat }}=\frac{M W h}{\mathrm{~m}^{2}} \cdot 100 \mathrm{~m}^{2} \cdot \text { n. build }
\end{gathered}
$$

$$
\begin{gathered}
\text { n.truck }=\frac{\text { ton }_{\text {goods }}}{\text { ton }_{\text {goods }} / \text { truck }} \\
M W h=\frac{M W h}{\text { inhab }} \cdot n \cdot \text { inhabit } \\
M W h_{\text {heat }}=\frac{M W h}{m^{2}} \cdot \frac{m^{2}}{e m p l} \cdot \text { nr.empl }
\end{gathered}
$$

where " $i$ " represents gasoline, diesel, LPG. Finally, it is possible to find the energy flow thanks to the conversion coefficient $\left(M W h / l_{f u e l}\right)$ calculated for each fuel starting from relative values of lower heating value $\left(\mathrm{kWh} / \mathrm{kg}_{\text {fuel }}\right)$ and density $\left(\mathrm{kg}_{\text {fuel }} \mathrm{l}_{\text {fuel }}\right)$. For commercial transport (public and private), the ratio between the regional estimates related to wheeled goods handling (tongoods) and a truck's medium load (tongoods/truck), [21], [22], gives the number of trucks in circulation in the regional area, (eq. 2). This value ( . truck) once the average distance covered by goods $(\mathrm{km})$ and the average fuel consumption of truck $(\mathrm{km} / \mathrm{l})$ are known, allows to calculate fuels (mainly diesel) consumption $(l)$ in the regional area, (eq. 3), related to Municipality thanks to inhabitants. Finally, as already done for private vehicles, the energy flow is calculated thanks to the conversion coefficient $\left(M W h / l_{\text {fuel }}\right)$.

Residential sector: Electricity consumptions have been determined by estimating average consumption per inhabitant in the specific geographical region (MWh/inhabit), starting from statistics of TERNA (Italian energy TSO), [23]: by multiplying this value and the inhabitants' number in the Municipality ( $n r$. inhabit), the respective electrical energy flow is obtained, (eq. 4). The heating consumptions are determined using ISTAT (Italian Central Statistics Institute) dataset referred to number of municipal residential buildings, [22], distributed in terms of number of floors above ground and per construction year. Starting from this classification, 28 categories have been created, developing two matrix $4 \times 7$ where the lines are the variation of floors above ground number $(1,2,3,4$ or more) and the columns

\begin{tabular}{|c|c|c|c|c|c|c|c|c|c|c|c|c|c|c|}
\hline & \multicolumn{2}{|c|}{ before 1945} & \multicolumn{2}{|c|}{$1946-1960$} & \multicolumn{2}{|c|}{$1961-1970$} & \multicolumn{2}{|c|}{$1971-1980$} & \multicolumn{2}{|c|}{$1981-1990$} & \multicolumn{2}{|c|}{$1991-2001$} & \multicolumn{2}{|c|}{ after 2001} \\
\hline & n. & $\mathbf{M W h} / \mathrm{m}^{2}$ & n. & $\mathbf{M W h} / \mathbf{m}^{2}$ & n. & $\mathbf{M W h} / \mathbf{m}^{2}$ & n. & $\mathrm{MWh} / \mathrm{m}^{2}$ & n. & $\mathbf{M W h} / \mathbf{m}^{2}$ & n. & $\mathbf{M W h} / \mathrm{m}^{2}$ & n. & $\mathbf{M W h} / \mathrm{m}^{2}$ \\
\hline 1 floor & 451 & 673 & 344 & 696 & 335 & 507 & 335 & 519 & 335 & 382 & 176 & 159 & 176 & 159 \\
\hline 2 floor & 278 & 849 & 278 & 878 & 223 & 639 & 223 & 655 & 219 & 482 & 113 & 201 & 113 & 201 \\
\hline 3 floor & 193 & 221 & 193 & 229 & 186 & 167 & 186 & 171 & 175 & 126 & 92 & 52 & 92 & 52 \\
\hline$\geq 4$ floor & 178 & 97 & 178 & 100 & 168 & 73 & 168 & 75 & 153 & 55 & 81 & 23 & 81 & 23 \\
\hline
\end{tabular}
indicate the correspondent intervals of years of construction (before 1945, 1946-1961, 1962-1971, 1972-1981, 19821991, 1991-2001, after 2001): in particular, for each category, the respective number of municipal residential buildings ( $n$. buildings), and the energy requests $\left(M W h / m^{2}\right)$, Table 2 have been linked.

Table 2. Number of residential building and energy request for Avezzano, distributed for number of floors above ground and construction year. 
To evaluate the thermal consumption $\left(M W h / \mathrm{m}^{2}\right)$, a specific mathematical model has been used, starting from geographical position, construction materials and age of the buildings, and making suitable hypotheses about the average surface exposed for each floor $\left(100 \mathrm{~m}^{2}\right)$. Finally, the energy flow for the heating system of each category and of the whole Municipality is calculated (eq. 5), reconsidering the hypothesis about the average extension of each flat. In order to include the use of hot water for domestic uses (hygienic, sanitary, cooking, etc.), the correspondent energy associated has been accounted in a lumped form estimating the overall contribution equal to $10 \%$ of the consumptions for space heating, [24].

Tertiary sector: Electricity energy consumption in the tertiary sector was estimated by knowing the provincial average accounting of electrical consumption $(M W h)$, and dividing by the inhabitants. The thermal energy flow, (eq. 6) is calculated by multiplying the numbers of tertiary sector's operators (n. empl) in the Municipality, the energy demand for each place unit area $\left(M W h / \mathrm{m}^{2}\right)$, calculated with the same mathematical model used in the previous paragraph and the estimated surface for each employee $\left(\mathrm{m}^{2} / \mathrm{empl}\right)$.

Municipal fleet, public transport, municipal public lighting and municipal buildings: For this remaining sector, the calculation of the energy flows started from collected and processed data, provided directly by the Municipality, regarding the vehicles owned for transportation and to guarantee municipal services. For the municipal fleet and public transport, the analysis started from the fuel consumption $\left(l_{\text {fuel }}\right)$, converted by specific conversion coefficients into MWh. For the municipal public lighting, the Municipality has specific consumptions easily determined. In the same way, for municipal buildings, the electrical energy flow is calculated form the consumption monitored from the bills, and the heating energy flows from the thermal consumption.

\subsection{Emission $\mathrm{CO}_{2}$ calculation}

Once the electrical and heating flow are calculated for each sector, the corresponding $\mathrm{CO}_{2}$ emissions have been calculated considering the emission factors (ton $\mathrm{CO}_{2} / \mathrm{MWh}$ ) specified by SEAP guidelines, referred to 2005, [25]. In particular, the energy flows associated to the different fuels' consumption (gas, diesel and LPG) in the reference area are taken into account where the amount of biofuels' use has been subtracted after having discounted the primary energy needed for their production and use. Similarly, the national target on the use of Renewable Energy Sources (RES) in the transportation sector, [26], was considered in order to obtain a specific percentage to be discounted. The computation of $\mathrm{CO}_{2}$ emissions in buildings, equipment and systems, has two different paths: a) for the electrical consumption, the emission coefficient that takes into account the part of electrical energy produced by renewable energy source, [27]; b) the heating energy flow has been distributed by different energy vectors used in the territory of the Municipality, [28], [29], after the allocation of the energy section produced by RES systems thanks to GSE database, [30]. The methodology described above was used to elaborate the SEAP of the Municipality of Avezzano and the quantitative monitoring phases were carried out up to the drafting of the MEI.

\subsection{BEI for the Municipality of Avezzano}

Avezzano is the second largest Municipality by extension and population density in Province of L'Aquila. Presently it has about 42,000 inhabitants (demonstrating a growth since 2005 with about 39,000 inhabitants at that time) with a density of 408 inhabit $/ \mathrm{km}^{2}$. The altitude varies from a minimum of $652 \mathrm{~m}$ to a maximum of 1,398 meters above sea level. It extends into "Plateau of the Fucino Lake", a territory created after the drainage of the old no longer existing "Fucino Lake". The area has a continental climate, it's included in climatic "zone E", $2101 \leq$ degree days $\leq 3000$, this means that the heating system can be switched on 14 hours daily from 15 October to 15 April.

An important event that characterized the history, useful to define the building characterization, was the earthquake of 1915. This event remains influential in modern architecture and urban planning of the city: in fact, in the 2017, of the 8,748 residential buildings in the municipality, only 50 dates back to 1918 . Another aspect is that the $70 \%$ of the buildings have a maximum of 2 floors, this because the Italian law introduced in the 1926 a maximum number of floors in seismic zone. As already observed, the city's economy is based on agroindustry, tourism and tertiary sector (from 2005 to 2017 the numbers of the employees in tertiary has grown from 4,947 to 6,544) servicing the light industrial districts nearby. The analysis of the data in terms of $\mathrm{CO}_{2}$ emission referred to 2005, Table 3, revealed a slightly higher contribution of subtotal "buildings, equipment and facilities sector" $\left(109,248.9\right.$ tonCO $\left.{ }_{2}\right)$ than subtotal "transport sector" $(90,072.9$ tonCO 2$)$ : in the first are predominant the emissions from residential buildings $(40.4 \%)$ and tertiary buildings and equipment (12.7\%), instead, in the second, the data highlights an important contributions from private and commercial transport (with its $44.9 \%$ represent the bigger contribute). The remaining sector representing a negligible percentage of total emission, are crosshatched because the calculation of its energy flows 
started from collected and processed data, and not from the model described in the chapter 3.2. The total emission for the year 2005 in Avezzano was 199,321.8 tonCO ${ }_{2}$, with a goal set by "Climate \& energy package" of $20 \%$ from 2005 levels defined at 39,864.4 $\mathrm{tCO}_{2}$.

Table 3. Avezzano municipal BEI 2005 for final energy consumption (a) and $\mathrm{CO}_{2}$ emissions (b).

\begin{tabular}{|c|c|c|c|c|c|c|c|c|c|c|}
\hline \multicolumn{11}{|l|}{2005} \\
\hline \multirow[b]{3}{*}{ Sector } & \multicolumn{10}{|c|}{ Final energy consumption [MWh] } \\
\hline & \multirow[b]{2}{*}{ Electricity } & \multicolumn{4}{|c|}{ Fossil fuels } & \multirow[b]{2}{*}{ Biofuel } & \multirow[b]{2}{*}{$\begin{array}{c}\text { Other } \\
\text { biomass }\end{array}$} & \multirow[b]{2}{*}{$\begin{array}{c}\text { Solar } \\
\text { thermal }\end{array}$} & \multirow[b]{2}{*}{$\begin{array}{c}\text { Heat } \\
\text { pumps }\end{array}$} & \multirow[b]{2}{*}{ Total } \\
\hline & & $\begin{array}{c}\text { Natural } \\
\text { gas }\end{array}$ & Liquid gas & Diesel & Gasoline & & & & & \\
\hline \multicolumn{11}{|l|}{ BUILDINGS, EQUIPMENT/FACILITIES } \\
\hline Municipal buildings, equipment/facilities & 9040 & 66570 & & & & & & & & $7.561,0$ \\
\hline Tertiary (non municipal) buildings, equipment/facilities & $40.098,3$ & $29.682,0$ & & & & & & & & $69.780,3$ \\
\hline Residential buildings & $38.589,2$ & $227.212,1$ & $38.870,5$ & $26.448,0$ & & & $72.531,5$ & 0,0 & 0,0 & $403.651,3$ \\
\hline Public lighting & 31640 & & & & & & & & & $3.164,0$ \\
\hline Subtotal buildings, equipment/facilities & $82.755,5$ & $263.551,1$ & $38.870,5$ & $26.448,0$ & & & $72.531,5$ & & & $484.156,6$ \\
\hline \multicolumn{11}{|l|}{ TRANSPORT } \\
\hline Municipal fleet & & & & 5972 & 2751 & 2,8 & & & & 875,1 \\
\hline Public transport & & & & 152699 & & 7,1 & & & & $1.534,0$ \\
\hline Private and commercial transport & & & $7.948,3$ & $253.565,2$ & $79.916,8$ & $1.184,7$ & & & & $342.615,0$ \\
\hline Subtotal transport & & & $7.948,3$ & $255.689,2$ & $80.191,9$ & $1.194,6$ & & & & $345.024,1$ \\
\hline Total & $82.755,5$ & $263.551,1$ & $46.818,8$ & $282.137,2$ & $80.191,9$ & $1.194,6$ & $72.531,5$ & & & $\mathbf{8 2 9 . 1 8 0 , 7}$ \\
\hline \multirow[b]{3}{*}{ Sector } & \multicolumn{10}{|c|}{$\mathrm{CO} 2$ emissions [tonCO2] } \\
\hline & \multicolumn{5}{|c|}{ Fossil fuels } & \multirow[b]{2}{*}{ Biofuel } & \multirow[b]{2}{*}{$\begin{array}{c}\text { Other } \\
\text { biomass }\end{array}$} & \multirow[b]{2}{*}{$\begin{array}{l}\text { Solar } \\
\text { thermal }\end{array}$} & \multirow[b]{2}{*}{$\begin{array}{c}\text { Heat } \\
\text { pumps }\end{array}$} & \multirow[b]{2}{*}{ Total } \\
\hline & Electricity & $\begin{array}{l}\text { Natural } \\
\text { gas }\end{array}$ & Liquid gas & Diesel & Gasoline & & & & & \\
\hline \multicolumn{11}{|l|}{ BUILDINGS, EQUIPMENT/FACILITIES } \\
\hline Municipal buildings, equipment/facilities & 4366 & 13447 & & & & & & & & $1.781,3$ \\
\hline Tertiary (non municipal) buildings, equipment/facilities & $19.367,5$ & $5.995,8$ & & & & & & & & $25.363,3$ \\
\hline Residential buildings & $18.638,6$ & $45.896,8$ & $8.979,1$ & $7.061,6$ & & & 0,0 & 0,0 & 0,0 & $80.576,1$ \\
\hline Public lighting & 15282 & & & & & & & & & $1.528,2$ \\
\hline Subtotal buildings, equipment/facilities & $39.970,9$ & $53.237,3$ & $8.979,1$ & $7.061,6$ & & & 0,0 & & & $109.248,9$ \\
\hline \multicolumn{11}{|l|}{ TRANSPORT } \\
\hline Municipal fleet & & & & 1595 & 685 & 0,0 & & & & 228,0 \\
\hline Public transport & & & & 4077 & & 0,0 & & & & 407,7 \\
\hline Private and commercial transport & & & $1.836,1$ & $67.701,9$ & $19.899,3$ & 0,0 & & & & $89.437,2$ \\
\hline Subtotal transport & & & $1.836,1$ & $68.269,0$ & $19.967,8$ & 0,0 & & & & $90.072,9$ \\
\hline Total & $39.970,9$ & $53.237,3$ & $10.815,1$ & $75.330,6$ & $19.967,8$ & 0,0 & 0,0 & & & $199.321,8$ \\
\hline Emission factors [tonCO2/MWh] & 0,483 & 0,202 & 0,231 & 0,267 & 0,249 & 0,000 & 0,000 & 0,000 & 0,000 & \\
\hline
\end{tabular}

\section{Monitoring phases and planning tools for the Municipality of Avezzano}

\subsection{SEAP monitoring process}

The subscription of the Covenant agreement expresses the achievement of a specific and quantitative goal, set by the European Union, by 2020. This choice required a continuous and detailed campaign of monitoring actions, consumption and implementation actions frequently up-dated. In fact, during the implementation period of the interventions (2013-2020), the SEAP guidelines provide a monitoring phase, every two-years, that verifies and validates the energy and environmental planning tools. These phases require the implementation of two different procedures, an "Intervention Report" and a "Complete Report", mandatory for the CoM signatories and necessary condition to maintain adhesion to the project, Table 4, [31]. For the implementation of this phases, DIIIE has stipulated, for each Municipality, a specific collaboration agreement for the development of the necessary procedures, including Avezzano. The SEAP monitoring involves specific implementation steps to optimally fulfill the activities envisaged for the preparation of the relative specific reports. A first qualitative (and partly quantitative) analysis was presented, for all the 108 municipalities, in a previous paper, [32], following these steps: a) SEAP check and online update: identify and analyze the situation as a reference state; b) Start monitoring phase: implementation, reporting and monitoring check-list for Municipalities; c) Data collection: from check-list with the state of implementation of the actions; d) Elaboration and loading data on official "Covenant of Mayors" website; e) "Intervention Report": quantitative framework for municipalities which summarizes the progresses. 
This paper analyzes from a qualitative point of view SEAP updating, quantifying the single consumptions for each energy sector, drafting a new MEI for a specific year: the data analysis revealed the state of the implementation of the actions in 2017, in order to have a global analysis of municipal state and interventions and to verify the correct planning process to the 2020 goal $\mathrm{CO}_{2}$ reduction of $20 \%$. Table 5 show the elaborations concerning the MEI in terms of total energy consumption $(\mathrm{MWh})$ and emissions $\left(\right.$ ton $\left.\mathrm{CO}_{2}\right)$.

The implementation methodology for this phase follows the afore mentioned methodological approach.

Table 4. SEAP monitoring methodology.

\begin{tabular}{ccclc}
\hline Methodology & Period & \multicolumn{1}{c}{ Part } & Activity \\
\hline \multirow{2}{*}{$\begin{array}{c}\text { Intervention } \\
\text { Report }\end{array}$} & $\begin{array}{c}\text { At least every } \\
\text { 2 years }\end{array}$ & Part I. & General strategy & $\begin{array}{l}\text { Changes made to the general strategy and updated data on } \\
\text { human and financial resources. }\end{array}$ \\
\cline { 3 - 5 } & & Part II. & Sustainable Energy Action Plan & Status of implementation of the actions and any revisions. \\
\hline \multirow{2}{*}{$\begin{array}{c}\text { Complete } \\
\text { Report }\end{array}$} & $\begin{array}{c}\text { At least every } \\
\text { 4 years }\end{array}$ & Part I. & General strategy & $\begin{array}{l}\text { Changes made to the general strategy and updated data on } \\
\text { human and financial resources. }\end{array}$ \\
\cline { 3 - 5 } & & Part II. & Emission Inventory & Monitoring Emissions Inventory (MEI). \\
\cline { 3 - 5 } & Part III. & Sustainable Energy Action Plan & Status of implementation of the actions and any revisions. \\
\hline
\end{tabular}

\subsection{Monitoring Emission Inventory}

For the $\mathrm{CO}_{2}$ emission associated to MEI 2017, an analysis has been done in order to compare the two different balance. MEI reveal a contribution for subtotal "buildings, equipment and facilities" sector equal to $152,340.3$ tonCO 2 , with the main higher quantity for residential buildings (50.5\%) and tertiary buildings and equipment at $18.8 \%$, Figure 1 . Subtotal "transport sector" are equal to $107,771.7$ tonCO $\mathrm{CO}_{2}$ with the predominant emissions from private and commercial transport (29.0\%). The total emission for the year 2017 in Avezzano was 152,340.3 tonCO $\mathrm{CO}_{2}$ with a reduction of $23.5 \%$ from 2005 level ( -46.9 thousand tonCO $\mathrm{CO}_{2}$ ), that means have exceeded the target set by 2020 . Particularly the reduction has occurred in all sectors except for the "tertiary buildings and equipment", moreover in line with national trends, [33]. The comparative analysis between the emissions in BEI 2005 and in the MEI 2017, differentiated by sectors, shows how the sector with largest reductions in terms of $\mathrm{CO}_{2}$ was the "private and commercial transport" sub-sector, with around 45.5 thousand ton $\mathrm{CO}_{2}$ saved, Figure 2, mainly related to the reduction of fuel diesel consumption: these numbers are due to the strong reduction of wheeled goods handling in the regional territory (about 67 million ton in 2005 and 29.4 million in 2017), natural technological evolution, stringent regulations and to the car fleet revamping in the past 12 years.
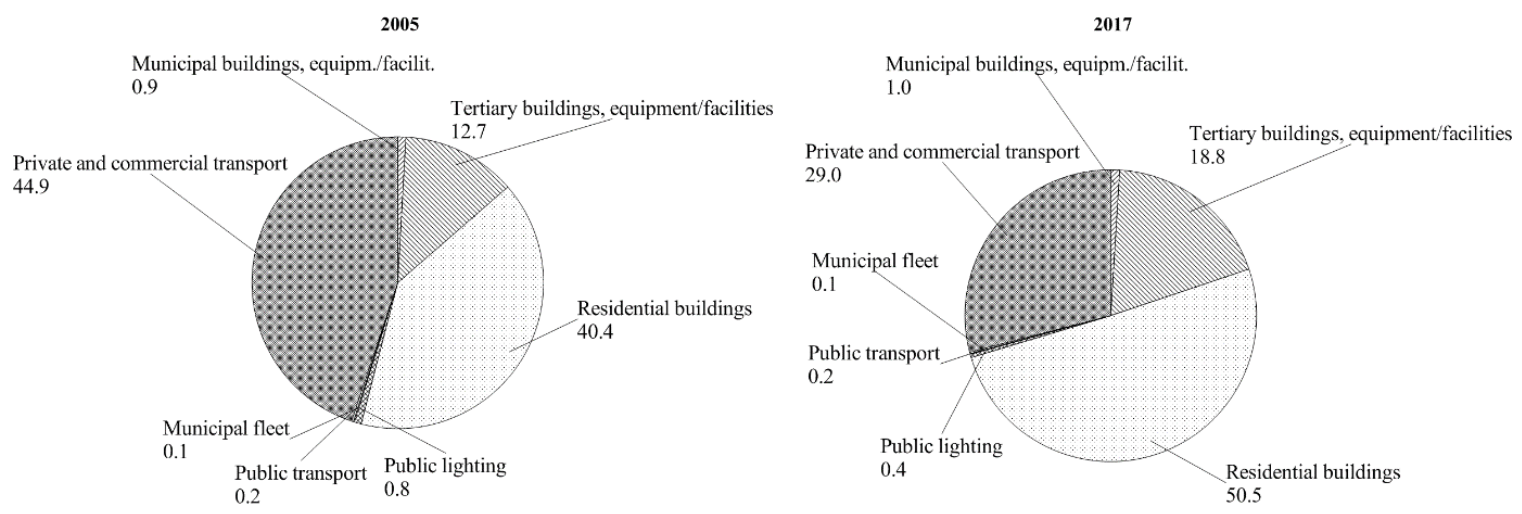

Figure 1: Percentage comparison between 2005 and 2017 for the different BEI and MEI categories.

The reduction percentage in this sub-sector was about $50.6 \%$, Figure 3 . The other transport sub-sectors, albeit with lower total emission, show important percentages of $\mathrm{CO}_{2}$ reductions: $-35.1 \%$ of public transport and $-62.0 \%$ of transport linked to the Municipality, Figure 3. Concerning the sector of buildings, the global $\mathrm{CO}_{2}$ reduction are much lower of transport ones: about -1.47 thousand respect 2005 values $(-1.4 \%)$ : even, in the tertiary buildings sub-section, an increase in emissions has been done (about $+13.2 \%$ ). In the residential buildings, the low reduction of $-4.5 \%$ also due to the increase in the population (and, therefore of global energy consumptions) but the positive contribution (which compensate this increase) has due to the replacement of the old LPG and diesel thermal plants and electricity boilers with gas plants with efficiency improvements and emission reductions, Figure 2. 
Table 5. Avezzano municipal MEI 2017 for final energy consumption (a) and $\mathrm{CO}_{2}$ emissions (b).

\begin{tabular}{|c|c|c|c|c|c|c|c|c|c|c|}
\hline \multicolumn{11}{|l|}{2017} \\
\hline \multirow[b]{3}{*}{ Sector } & \multicolumn{10}{|c|}{ Final energy consumption [MWh] } \\
\hline & \multirow[b]{2}{*}{ Electricity } & \multicolumn{4}{|c|}{ Fossil fuels } & \multirow[b]{2}{*}{ Biofuel } & \multirow[b]{2}{*}{$\begin{array}{c}\text { Other } \\
\text { biomass }\end{array}$} & \multirow[b]{2}{*}{$\begin{array}{c}\text { Solar } \\
\text { thermal }\end{array}$} & \multirow[b]{2}{*}{$\begin{array}{c}\text { Heat } \\
\text { pumps }\end{array}$} & \multirow[b]{2}{*}{ Total } \\
\hline & & $\begin{array}{l}\text { Natural } \\
\text { gas }\end{array}$ & Liquid gas & Diesel & Gasoline & & & & & \\
\hline \multicolumn{11}{|l|}{ BUILDINGS, EQUIPMENT/FACILITIES } \\
\hline Municipal buildings, equipment/facilities & 8998 & 60279 & & & & & & & & $6.867,8$ \\
\hline Tertiary (non municipal) buildings, equipment/facilities & $62.979,9$ & $39.264,0$ & & & & & & & & $102.243,9$ \\
\hline Residential buildings & $42.083,9$ & $310.316,4$ & $1.764,2$ & 0,0 & & & $106.074,1$ & 33,2 & 688,9 & $460.960,7$ \\
\hline Public lighting & 17668 & & & & & & & & & $1.766,8$ \\
\hline Subtotal buildings, equipment/facilities & $107.670,6$ & $355.608,4$ & $1.764,2$ & 0,0 & & & $106.074,1$ & 33,2 & 688,9 & $571.839,3$ \\
\hline \multicolumn{11}{|l|}{ TRANSPORT } \\
\hline Municipal fleet & & & & 2303 & 1013 & 8,7 & & & & 340,3 \\
\hline Public transport & & & & 9911 & & 37,5 & & & & $1.028,6$ \\
\hline Private and commercial transport & & & $9.758,8$ & $128.199,2$ & $31.059,4$ & $4.848,0$ & & & & $173.865,3$ \\
\hline Subtotal transport & & & $9.758,8$ & $129.420,6$ & $31.160,7$ & $4.894,2$ & & & & $175.234,2$ \\
\hline Total & $107.670,6$ & $355.608,4$ & $11.523,0$ & $129.420,6$ & $31.160,7$ & $4.894,2$ & $106.074,1$ & 33,2 & 688,9 & $747.073,5$ \\
\hline \multirow[b]{3}{*}{ Sector } & \multicolumn{10}{|c|}{$\mathrm{CO} 2$ emissions [tonCO2] } \\
\hline & \multicolumn{5}{|c|}{ Fossil fuels } & \multirow[b]{2}{*}{ Biofuel } & \multirow[b]{2}{*}{$\begin{array}{c}\text { Other } \\
\text { biomass }\end{array}$} & \multirow[b]{2}{*}{$\begin{array}{l}\text { Solar } \\
\text { thermal }\end{array}$} & \multirow[b]{2}{*}{$\begin{array}{c}\text { Heat } \\
\text { pumps }\end{array}$} & \multirow[b]{2}{*}{ Total } \\
\hline & Electricity & $\begin{array}{c}\text { Natural } \\
\text { gas }\end{array}$ & Liquid gas & Diesel & Gasoline & & & & & \\
\hline \multicolumn{11}{|l|}{ BUILDINGS, EQUIPMENT/FACILITIES } \\
\hline Municipal buildings, equipment/facilities & 272 & 12176 & & & & & & & & $1.494,8$ \\
\hline Tertiary (non municipal) buildings, equipment/facilities & $20.783,4$ & $7.931,3$ & & & & & & & & $28.714,7$ \\
\hline Residential buildings & $13.887,7$ & $62.683,9$ & 407,5 & 0,0 & & 0,0 & 0,0 & 0,0 & 0,0 & $76.979,1$ \\
\hline Public lighting & 583,1 & & & & & & & & & 583,1 \\
\hline Subtotal buildings, equipment/facilities & $35.531,3$ & $71.832,9$ & 407,5 & 0,0 & & 0,0 & 0,0 & 0,0 & 0,0 & $107.771,7$ \\
\hline \multicolumn{11}{|l|}{ TRANSPORT } \\
\hline Municipal fleet & & & & $6: 5$ & 252 & 0,0 & & & & 86,7 \\
\hline Public transport & & & & 264,6 & & 0,0 & & & & 264,6 \\
\hline Private and commercial transport & & & $2.254,3$ & $34.229,2$ & $7.733,8$ & 0,0 & & & & $44.217,2$ \\
\hline Subtotal transport & & & $2.254,3$ & $34.555,3$ & $7.759,0$ & 0,0 & & & & $44.568,6$ \\
\hline Total & $35.531,3$ & $71.832,9$ & $2.661,8$ & $34.555,3$ & $7.759,0$ & 0,0 & 0,0 & 0,0 & 0,0 & $152.340,3$ \\
\hline Emission factors [tonCO2/MWh] & 0,330 & 0,202 & 0,231 & 0,267 & 0,249 & 0,000 & 0,000 & 0,000 & 0,000 & \\
\hline
\end{tabular}

In the sectors in which the consumptions and the related emissions are directly affected by the Public Administration (crosshatched cells in Table 5), public buildings and public lighting have seen reductions in terms of percentages, with, respectively, $16.1 \%$ and $61.8 \%$ : this thanks to efficiency policies by the PA undertaken in recent years which led to get a total reduction of $1516 \mathrm{tCO}_{2}$.
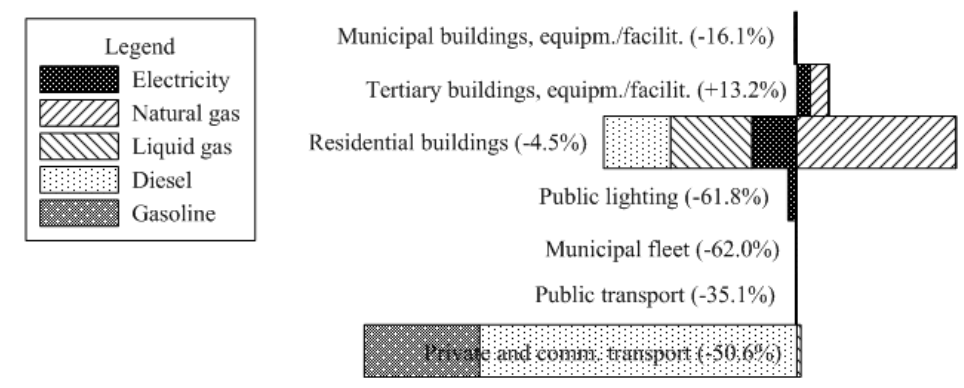

Total (-23.6\%)

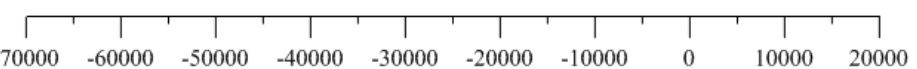

Figure 2: Comparison of $\mathrm{CO}_{2}$ emissions by sectors, sources [tonCO2] and global reduction $[\%]$.

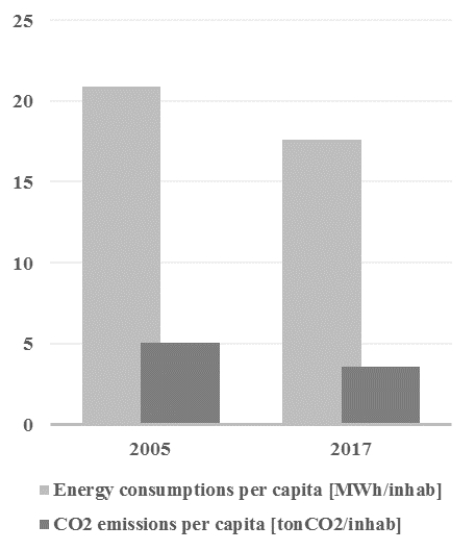

Figure 3: Per capita energy and $\mathrm{CO}_{2}$ trend. 
Also, the transport sector for municipal fleet and public transport, show global reductions of, respectively, $-62.0 \%$ and $-35.1 \%$, Figure 2 .

Figure 3 shows energy consumptions per capita and $\mathrm{CO}_{2}$ emission reductions per capita accounting to BEI and MEI: consumptions are reduced of $3.3 \mathrm{MWh}$ per capita in the 12 years, emissions are reduced from 5.0 tonCO $\mathrm{O}_{2}$ to 3.6 ton $\mathrm{CO}_{2}$, for about 1.4 tonCO $\mathrm{CO}_{2}$ per capita. These data allowed to compare the results obtained with the goals of the EC: in $2020 \mathrm{UE}$ expects a reduction of emission per capita from 5.6 tonCO $\mathrm{O}_{2}$ to 4.4 tonCO $\mathrm{C}_{2}$.

\subsection{Local energy production}

The reduction in emissions was also achieved thanks to the local production of energy from RES, in electrical and thermal sectors. In detail, the power generated from RES in Avezzano includes only photovoltaic (PV) and biogas [30]. A biogas plant installed in 2012 has a rated power of $999 \mathrm{~kW}$ and a production of 7,992 MWh/y, about $26 \%$ of total local production. For PV plants, based on local statistical data, it was possible to calculate the solar electrical production defining local working hours (1305 h/y, [34]) for a total of 12,075.9 MWh in 2017, Table 6.

Table 6. Avezzano municipal MEI 2017 for local energy production.

\begin{tabular}{cc}
\hline $\mathbf{2 0 1 7}$ & \\
\hline $\begin{array}{c}\text { Local electricity production plants (ETS and } \\
\text { large-scale plants }>\mathbf{2 0} \text { MW not recommended) }\end{array}$ & $\begin{array}{c}\text { Electricity produced [MWh] } \\
\text { from renewable sources }\end{array}$ \\
\hline Wind & 0,0 \\
Hydroelectric & 0,0 \\
Photovoltaics & $22.941,7$ \\
Biogas & $7.992,0$ \\
\hline Total & $\mathbf{3 0 . 9 3 3 , 7}$ \\
\hline
\end{tabular}

\begin{tabular}{cc}
\hline Local heat/cold production plants & $\begin{array}{c}\text { Heat/cold produced [MWh] } \\
\text { from renewable sources }\end{array}$ \\
\hline Solar thermal & 33,2 \\
Bioenergy & $12.042,7$ \\
Heat pumps & 688,9 \\
\hline Total & $\mathbf{1 2 . 0 7 5 , 9}$ \\
\hline
\end{tabular}

An important development of the installation of PV in Avezzano occurred up to 2013 thanks above all to the dedicated incentives, both for small and large plants. Excluding these large plants (sizing 1-4 MW, installed even after the expiration of the incentives due to bureaucratic delays) this development was mainly linked to small-sized domestic plants, till to reach a total installed power of about $30 \mathrm{MW}$ at the end of 2017. For the heating sectors solar thermal, bioenergy and heat pump plants have been considered, all of them build after 2005.

About the solar thermal is known the total surface installed of solar collectors and the power produced in Italy, [34], so was possible to calculate the medium performance factor $599.6 \mathrm{kWh} / \mathrm{m}^{2}$. This value was similar to the ones reported in the technical report and statistics, [35]. Solar thermal there are $599.6 \mathrm{~m}^{2}$ (plate collectors), all for private entities (domestic or small business applications), with an average surface less than $15 \mathrm{~m}^{2}$, with an estimated production of 33.2 MWh (thanks to a local performance factor of $599.6 \mathrm{kWh} / \mathrm{m}^{2}$. Bioenergy plant installed amount $7.1 \mathrm{MW}$ with a production of 12,042.7 MWh, using a utilisation factor of $1700 \mathrm{~h} / \mathrm{y}$, [36]. Heat pumps installed in Avezzano had useful heat output values of $0.41 \mathrm{MW}$, the local heating laws provide for a utilisation factor that was $1700 \mathrm{~h}$, so the heat pumps produced $688.9 \mathrm{MWh}$. Total heat energy produced in 2017 was estimated close to $12,765 \mathrm{MWh}$. This datum regards bioenergy (94.3\%), heat pumps (5.4\%) and solar thermal collectors $(0.3 \%) . c \%)$. Only $3 \%$ of the consumption in the heating sector was covered by renewable sources, instead, the nationally value was $20.1 \%$, [37].

\section{Conclusions}

The editing of a Sustainable Energy Action Plan (SEAP) is the first step for a correct planning and energy management of local territories. This Plan requires a continuous monitoring of the actions carried out by the Administrations, with different degree of detail and accounting, until the end of the "Covenant of Mayors" program, the actions which at least decrease the distance to the target referred to the $\mathrm{CO}_{2}$ emission. The paper offers a procedure for SEAP design and monitoring orienting year by year how to reach the EU target and putting in evidence which are the choices more convenient to reach the reduction's goal. A methodological description and data analysis for the Municipality of Avezzano, a medium-size City of the Province of L'Aquila, in Italy, was presented in order describe the state of the art in terms of energy consumption and emissions at reference year (2005). The aim of the SEAP is a reduction of $20 \%$ of the $\mathrm{CO}_{2}$ emissions, by 2020: so, the quantitative dimension of the reduction was fixed. In 2005, the global emission for the Municipality were about 200 thousand tonCO $\mathrm{C}_{2}$, corresponding to about $830 \mathrm{GWh}$ of local energy consumptions. The SEAP monitoring at 2017 has been derived: it shows the dynamic development of the energy needs and the efforts to reduce $\mathrm{CO}_{2}$ emissions, updating and finalizing the local emissions to the goals of the European Commission. Present status shows a global reduction of about 47 thousand tonCO $\mathrm{CO}_{2}$, with a reduction of 
$23.6 \%$ with respect to the 2005 data, widely within the 2020 target. This work is the first step of an important new future planning action requested by the European Commission after the "Covenant of Mayors" project: it is referred as SECAP (Sustainable Energy and Climate Action Plan) that will lead the Society by 2030 to be resilient to Climate Changes by implementing on the Territory mitigation and adaptation actions.

\section{Acknowledgments}

This work was carried out as part of an institutional cooperation with the Municipality of Avezzano whose policy makers are truly acknowledged. A special thanks is due to Dr. Stefano Di Fabio for the support given for data collection and fruitful discussions.

\section{References}

1. "Transforming our world: the 2030 Agenda for Sustainable Development", A/RES/70/1. United Nation, 2015.

2. Directive 2009/29/EC of the European Parliament and of the Council of 23 April 2009.

3. Covenant Official Text. Retrieved from http://www.eumayors.eu/IMG/pdf/covenantofmayors text en.pdf.

4. Schenone, C., Delponte, I., \& Pittaluga, I. (2015). The preparation of the Sustainable Energy Action Plan as a city-level tool for sustainability: The case of Genoa. Journal of Renewable and sustainable energy, 7(3), 033126.

5. Nuss-Girona, Sergi, et al. "The SEAP in the city of Girona, a crossroads between boldness and pragmatism." Local Environment 21.4 (2016): 476-503.

6. Marquez-Ballesteros, Maria-Jose, et al. "Measuring urban energy sustainability and its application to two Spanish cities: Malaga and Barcelona." Sustainable cities and society 45 (2019): 335-347.

7. Matak, Nikola, and Goran Krajačić. "Assessment of mitigation measures contribution to CO2 reduction in sustainable energy action plan." Clean Technologies and Environmental Policy (2019): 1-14.

8. Coelho, Silvia, et al. "Sustainable energy action plans at city level: A Portuguese experience and perception." Journal of Cleaner Production 176 (2018): 1223-1230.

9. Theodoridou, I., Mermigas, A., Christodoulou, A., Kanouras, S., \& Kokkinidou, R. (2020, January). Towards climate change mitigation and adaptation in cities-the role of Greek Municipalities and Prefectures. Findings and outcomes from the EMPOWERING Project. In IOP Conference Series: Earth and Environmental Science (Vol. 410, No. 1, p. 012008). IOP Publishing.

10. Fenton, Paul, et al. "Sustainable Energy and Climate Strategies: lessons from planning processes in five municipalities." Journal of Cleaner Production 98 (2015): 213-221.

11. Bernardo, Giovanni, and Simone D’Alessandro. "Societal implications of sustainable energy action plans: from energy modelling to stakeholder learning." Journal of Environmental Planning and Management 62.3 (2019): 399-423.

12. Official website of "Covenant of Mayors": (https://www.eumayors.eu/).

13. Lombardi, M., Pazienza, P., \& Rana, R. (2016). The EU environmental-energy policy for urban areas: The Covenant of Mayors, the ELENA program and the role of ESCos. Energy Policy, 93, 33-40.

14. Regione Abruzzo, Delibera Giuta Regionale n.396 - Adesione al Covenant of Mayors, 17/05/2010.

15. Regione Abruzzo, D. G. R. n. 39, Implementazione sul territorio regionale delle azioni previste dal Patto dei Sindaci-Approvazione della ripartizione tra i Comuni d'Abruzzo delle risorse finanziarie assegnate all'ASSE II "Energia" del POR-FESR 2007-2013, 24/01/2011.

16. Boehnke, R. F., Hoppe, T., Brezet, H., \& Blok, K. (2019). Good practices in local climate mitigation action by small and medium-sized cities; exploring meaning, implementation and linkage to actual lowering of carbon emissions in thirteen municipalities in The Netherlands. Journal of cleaner production, 207, 630-644.

17. Delponte, I., Pittaluga, I., \& Schenone, C. (2017). Monitoring and evaluation of Sustainable Energy Action Plan: practice and perspective. Energy Policy, 100, 9-17.

18. Bertoldi, Paolo et al., "Existing Methodologies and Tools for the Development and Implementation of SEAP", (2010), JRC EC.

19. ISPRA - Istituto superiore per la protezione e la ricerca ambientale, "Analysis of European road transport data".

20. MIT - Ministero delle infrastrutture e dei trasporti, "National account of infrastructure and transport".

21. ACI - Automobile Club d'Italia, "Statistical yearbook". 
22. ISTAT - Istituto nazionale di statistica, "Census 2011".

23. TERNA - Rete Elettrica Nazionale, "statistical yearbook".

24. ENEA - Agenzia nazionale per le nuove tecnologie, l'energia e lo sviluppo economico sostenibile. "The numbers of energy," 2015.

25. A, Neves, et al., "Covenant of Mayors guidelines for Climate and Energy for the presentation of monitoring".

26. GSE - Gestore dei servizi energetici, "Energia nel settore Trasporti," 005-2018.

27. ISPRA - Istituto superiore per la protezione e la ricerca ambientale, "Atmospheric greenhouse gas emission factors in the national electricity sector and in the main countries Europeans".

28. ISTAT - Istituto nazionale di statistica, "Data and micro data, energy sector - household energy consumption".

29. Ministero Per Lo Sviluppo. Economico, "The national energy situation in 2018," 2019.

30. GSE “Atlaimpianti”, https://www.gse.it/dati-e-scenari/atlaimpianti.

31. Covenant of Mayors Office and JRC - European Commission, "Reporting Guidelines SEAP and Monitoring," 2014.

32. Cinocca A., Santini F., Cipollone R., "Monitoring methodologies and tools for the Sustainable Energy Action Plans to support the Public Administration.," Energy Procedia, vol. 148, 2018.

33. ENEA, Piano d'Azione Italiano per l'Efficienza Energetica.

34. Agrillo A., Surace V, Liberatore L., Benedetti L., "Solare fotovoltaico - rapporto statistico," Gestore dei Servizi Energetici S.p.A., 2019

35. Thomas Hostettler, Indagine di mercato dell'energia solare 2018, Schweizerischer Fachverband für Sonnenenergie.

36. Decreto interministeriale, Aggiornamento Conto termico, 16 febbraio 2016.

37. GSE - https://www.gse.it/dati-e-scenari/monitoraggio-fer/monitoraggio-nazionale/settore-termico. 